\title{
Peramalan Kurs Rupiah Terhadap US Dollar Menggunakan Metode Hibrid
}

\author{
I Nyoman Sumerta Yasa ${ }^{1)}$, I Ketut Gede Darma Putra ${ }^{2)}$, N.M.A.E.D Wirastuti ${ }^{3)}$
}

\begin{abstract}
Forecasting is an integral part of management decision-making activities. Forecasts are made generally based on the data of the past that were analyzed by using certain methods. Therefore in this research will predict time series data using Radial Basis Fuction, ARIMA and Double Exponential Smoothing using Matlab version 8.1. The data used is the daily selling rate of Rupiah against the US Dollar that started from January 2012 to March 2014. Of the three results forecast, will be used voting method to obtain the accuracy of strengthening or weakening the condition of the rupiah against the US dollar and also the prediction results are combined by hybrid methods. From the results of RBF forecasting, ARIMA, Double Exponential Smoothing obtained MAPE respectively 0.66\%, $3.32 \%$ and $0.94 \%$, while the accuracy of the conditions to strengthen weakened by $52.54 \%, 45.76 \%$ and $52.54 \%$. Of the voting result of strengthening and weakening conditions obtained an accuracy rate of $54.24 \%$ and after combined with methods hybrid obtained MAPE of $0.64 \%$ with an accuracy of $50.85 \%$. It can be seen that for accuracy strengthened and weakened conditions are best obtained by using the method of voting, while for the best MAPE obtained by hybrid methods. Hopefully this research can help in analyzing the fluctuation of the value of a particular currency movements at the time of transaction purchase of foreign currency.
\end{abstract}

Intisari-Peramalan adalah bagian integral dari kegiatan pengambilan keputusan manajemen. Ramalan yang dilakukan umumnya berdasarkan pada data masa lampau yang dianalisis dengan menggunakan metode- metode tertentu. Oleh karena itu, pada penelitan ini akan meramalkan data time series menggunakan metode Radial Basis Fuction, ARIMA dan Double Exponential Smoothing dengan menggunakan Matlab versi 8.1. Data yang digunakan adalah data kurs jual harian Rupiah terhadap US Dollar yang dimulai dari bulan Januari 2012 sampai dengan Maret 2014. Dari ketiga hasil ramalan, akan digunakan metode voting untuk memperoleh akurasi dari kondisi menguat atau melemahnya kurs rupiah terhadap US Dollar dan juga hasil ramalan digabungkan dengan metode hibrid. Dari hasil peramalan RBF, ARIMA, Double Exponential Smoothing diperoleh MAPE berturutturut $0,66 \%, 3,32 \%$ dan $0,94 \%$ sedangkan akurasi kondisi menguat melemah sebesar $52,54 \%, \mathbf{4 5 , 7 6 \%}$ dan $52,54 \%$. Dari hasil voting dari kondisi menguat dan melemahnya

\footnotetext{
${ }^{1}$ Mahasiswa Pascasarjana, S2 Teknik Elektro Universitas Udayana, Jln. PB. Sudirman Denpasar Bali 80232 INDONESIA (telp: 0361-239599; e-mail: nyoman_sumerta@yahoo.com)

2,3Dosen Pascasarjana, S2 Teknik Elektro Universitas Udayana, Jln. PB. Sudirman Denpasar Bali 80232 INDONESIA (telp: 0361-239599; e-mail: ikgdarmaputra@unud.ac.id, dewi.wirastuti@unud.ac.id)
}

I Nyoman Sumerta Yasa : Peramalan Kurs Rupiah ... kurs diperoleh akurasi sebesar $54,24 \%$ dan setelah digabungkan dengan metode hibrid diperoleh MAPE sebesar 0,64\% dengan akurasi sebesar $50,85 \%$. Dapat dilihat bahwa untuk akurasi kondisi menguat dan melemah yang terbaik diperoleh dengan menggunakan metode voting sedangkan untuk MAPE terbaik diperoleh dengan metode hibrid. Diharapkan penelitian ini dapat membantu dalam menganalisa fluktuasi dari pergerakan nilai mata uang tertentu pada saat transaksi jual beli valuta asing.

Kata Kunci- RBF, ARIMA, Double Exponential Smoothing, MAPE, Hibrid

\section{PENDAHULUAN}

Salah satu dari ciri kehidupan sekarang ini adalah bahwa seseorang kadangkala meramalkan sesuatu yang akan terjadi pada masa yang akan datang dan menyusun rencana yang sesuai dengan kejadian-kejadian yang diramalkan. Ramalan yang baik sudah pasti bukanlah ramalan yang berdasarkan atas spekulasi yang tidak beralasan, melainkan melalui perkiraan berdasarkan atas tingkah laku dari gejala yang sudah ada dan diamati secara berulang-ulang [1]. Misalnya peramalan nilai kurs mata uang tidak mungkin diperhitungkan dan diramalkan berdasarkan perkiraan semata-mata. Dengan pengamatan yang berulang - ulang pergerakan nilai kurs mata uang dapat diperhitungkan dan diramalkan dengan tepat dan teliti.

Terdapat sejumlah fenomena besar yang hingga saat ini hasilnya dapat diramalkan dengan presisi ketepatan yang cukup tinggi. Kemajuan dari suatu ilmu pengetahuan dan teknologi telah meningkatkan pengertian mengenai berbagai aspek lingkungan yang berakibat banyaknya peristiwa yang dapat diramalkan [2]. Pada metode statistika, salah satu metode peramalan yang kerap kali digunakan adalah teknik Exponential Smoothing yaitu menggunakan pemulusan datadata lampau, teknik Autoregression Integrated Moving Average (ARIMA) dan teknik jaringan syaraf tiruan dengan metode Radial Basis Fuction. Ramalan yang dilakukan umumnya berdasarkan pada data masa lalu yang dianalisa dengan menggunakan kaidah tertentu [3]. Untuk menentukan akurasi nilai peramalan akhir, digunakan teknik skema voting yaitu memilih dimana di antara ketiga hasil yang memiliki suara terbanyak (dua dari tiga) berdasarkan atas kondisi hasil ramalan (menguat atau melemah). Jadi jika dua dari tiga metode memberikan nilai ramalan menguat maka hasil ramalan menguat. Sebaliknya jika dua dari tiga metode memberikan nilai ramalan melemah maka hasil ramalan melemah. Dan untuk memperoleh Mean Absolute Percentace

p-ISSN:1693 - 2951; e-ISSN: 2503-2372

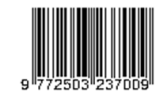


Error (MAPE) diperoleh dengan menggabungkan hasil dari ketiga metode peramalan dengan metode hibrid.

\section{METODE PERAMALAN}

\section{A. Radial Basis Function}

RBF didesain untuk membentuk pemetaan nonlinear dari variable input ke unit hidden layer dan pemetaan linear dari hidden layer ke output. Sehingga pada RBF dilakukan pemetakan input dari ruang berdimensi $\mathrm{p}$ ke output ruang berdimensi [4].

$$
s: \mathfrak{R}^{p} \rightarrow \mathfrak{R}^{1}
$$

Disain model RBF untuk pendekatan suatu fungsi adalah sebagai berikut :

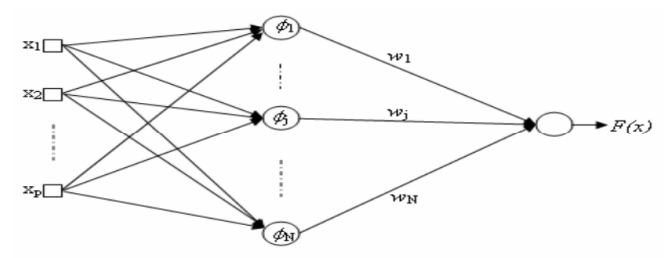

Gambar 1. Desain RBF network

Pada pemodelan RBF dilakukan dengan memilih suatu fungsi $F(x)$ sehingga (1) terpenuhi. Interpolasi input-output dengan melihat disain model RBF, maka dapat dinyatakan dengan:

$$
F(x)=\sum_{i=1}^{N} w_{i} \phi\left(\left\|x-x_{i}\right\|\right)
$$

Dimana $\left\{\phi\left(\left\|x-x_{i}\right\|\right) i=1,2,3, \ldots, N\right\}$ adalah himpunan fungsi nonlinear yang disebut fungsi radial basis (Radial Basis Function = RBF) dan $\|\cdot\|$ adalah norm jarak Euclid.

Fungsi basis radial yang paling sering digunakan adalah fungsi gaussian karena mempunyai sifat lokal, yaitu bila input dekat dengan rata-rata (pusat), maka fungsi akan menghasilkan nilai satu, sedangkan bila input jauh dari ratarata, maka fungsi memberikan nilai nol. Ada beberapa fungsi radial basis diantaranya adalah:

\section{Fungsi Thin Plate Spline}

$$
\phi(z)=(z-\mu)^{2} \log (z-\mu)
$$

2. Fungsi Multikuadratik

$$
\phi(z)=\left[(z-\mu)^{2}+\sigma^{2}\right]^{1 / 2}
$$

3. Fungsi Invers Multikuadratik

$$
\phi(z)=\left[(z-\mu)^{2}+\sigma^{2}\right]^{-1 / 2}
$$

$$
\begin{aligned}
& \text { 4. Fungsi Gaussian } \\
& \qquad \phi(z)=\exp \left[-(z-\mu)^{2} / \sigma^{2}\right]
\end{aligned}
$$

$\left.\begin{array}{l}\text { Apabila diketahui } \\ \left\{x_{i} \in \mathfrak{R}^{p} \mid i=1,2, \ldots, N\right\}\end{array}\right\} \begin{array}{cccc}\mathrm{N} & \text { buah titik } & \text { data } \\ \text { adalah } & \text { pusat dari } & \mathrm{RBF}, & \text { maka }\end{array}$ persamaan dapat ditulis :

$$
\left[\begin{array}{cccc}
\phi_{11} & \phi_{12} & \cdots & \phi_{1 N} \\
\phi_{21} & \phi_{22} & \cdots & \phi_{2 N} \\
\vdots & \vdots & \ddots & \vdots \\
\phi_{N 1} & \phi_{N 2} & \cdots & \phi_{N N}
\end{array}\right]\left[\begin{array}{c}
w_{1} \\
w_{2} \\
\vdots \\
w_{n}
\end{array}\right]=\left[\begin{array}{c}
d_{1} \\
d_{2} \\
\vdots \\
d_{N}
\end{array}\right]
$$

dimana $\phi_{i j}=\phi\left(\left\|x_{i}-x_{j}\right\|\right)$

$$
i, j=1,2,3, \ldots, N
$$

Bila (3) dinyatakan dalam bentuk persamaan matrik, persamaan (3) menjadi :

$$
\begin{aligned}
\mathbf{f} \mathbf{w} & =\mathbf{d} \\
\mathbf{d}= & {\left[\begin{array}{llll}
d_{1} & d_{2} & \cdots & d_{N}
\end{array}\right] } \\
\mathbf{w} & =\left[\begin{array}{llll}
w_{1} & w_{2} & \cdots & w_{N}
\end{array}\right] \\
\mathbf{f} & =\phi_{i j}
\end{aligned}
$$$$
\operatorname{dimana} \mathbf{d}=\left[\begin{array}{llll}
d_{1} & d_{2} & \cdots & d_{N}
\end{array}\right]
$$

matrik $\phi$ adalah matrik interpolasi yang definit positif dan mempunyai invers. Pendekatan dari suatu fungsi dengan menggunakan RBF dapat dilakukan dengan interpolasi untuk mendapatkan penyelesaian optimal dari ruang berdimensi tinggi ke dimensi yang lebih rendah. Poggio dan Girosi menyusun teknik standar yang disebut metode Galerkin [5]. Pada metode ini, $F(x)$ adalah suatu fungsi yang didekati dengan sejumlah basis lebih sedikit dibandingkan ukuran sampel, sehingga fungsi $F(x)$ pada (3) menjadi :

$$
F^{*}(x)=\sum_{i=1}^{M} w_{i} \phi_{i}(x)
$$

Dimana $\left\{\phi_{i}(x) \mid i=1,2, \ldots, M\right\}$ adalah himpunan fungsi basis baru yang diasumsikan bebas linear. Secara umum, himpunan fungsi basis baru lebih sedikit dibandingkan dengan banyak data $(\mathrm{M} \leq \mathrm{N})$ dan $w_{i}$ adalah bobot unit ke i ke output.

\section{B. ARIMA}

Wei (1994) menyebutkan bahwa pada proses stasioner $\left\{Z_{t}\right\}$, model ARIMA diklasifikasi menjadi tiga model standar [6], yaitu:

1. Model autoregressive (AR $(p) / \operatorname{ARIMA}(p, 0,0))$ :

$$
Z_{t}=\omega_{1} Z_{t-1}+\omega_{2} Z_{t-2}+\cdots+\omega_{p} Z_{t-p}+a_{t}
$$

2. Model moving average (MA $(q) / \operatorname{ARIMA}(q, 0,0))$ :

$$
Z_{t}=a_{t}-\theta_{1} a_{t-1}-\theta_{2} a_{t-2}-\cdots-\theta_{q} a_{t-q}
$$


3. Model autoregressive moving average (ARMA $(p, q) /$

$$
\begin{aligned}
& \operatorname{ARIMA}(p, 0, q)): \\
& \begin{aligned}
Z_{t}= & \omega Z_{t-1}+\omega_{2} Z_{t-2}+\cdots+\omega_{p} Z_{t-p}+a_{t}-\theta_{1} a_{t=1}- \\
& \theta_{2} a_{t-2}-\cdots-\theta_{q} a_{t-q}
\end{aligned}
\end{aligned}
$$

dengan $a_{t}$ adalah white noise $\left(a_{t} \sim N\left(0, \sigma_{a}^{2}\right)\right)$, dimana:

$$
\begin{aligned}
p & =\text { orde proses autoregressive } \\
q & =\text { orde proses moving average } \\
\omega & =\text { parameter proses autoregressive } \\
\theta & =\text { parameter proses moving average }
\end{aligned}
$$

Dalam keadaan tak stasioner, model deret waktu yang digunakan adalah model Autoregressive Integrated Moving Average (ARIMA $(p, d, q))$ yang didefinisikan dalam persamaan (8) [7]:

$$
\begin{gathered}
\nabla^{d} Z_{t}=\omega_{1} \nabla^{d} Z_{t-1}+\omega_{2} \nabla^{d} Z_{t-2}+\cdots+\omega_{p} \nabla^{d} Z_{t-p}+a_{t}- \\
\theta_{1} a_{t-1}-\theta_{2} a_{t-2}-\cdots-\theta_{q} a_{t-q} \\
\text { dengan } \nabla^{d} Z_{t}=\nabla^{d-1} Z_{t}-\nabla^{d-1} Z_{t-1} \text {, dan } \nabla^{0} Z_{t}=Z_{t} \\
\text { dimana: } \\
\nabla^{d} Z_{t}=\text { pembedaan (differencing) peubah } Z_{t} \\
d=\text { banyaknya pembedaan }
\end{gathered}
$$

Pembedaan dilakukan sebanyak $d$ kali sampai proses mencapai keadaan stasioner. Pembedaan ditujukan agar proses dapat dimodelkan dengan mengkonversi proses tak stasioner $\left\{Z_{t}\right\}$ menjadi proses stasioner $\left\{\nabla^{d} Z_{t}\right\}[8]$.

Langkah-langkah pemodelan ARIMA $(p, d, q)$, yaitu:
a. Identifikasi model
b. Pendugaan parameter
c. Pemeriksaan kelayakan model
d. Pemilihan model terbaik

\section{Double Exponential Smoothing}

Metode double exponential smoothing digunakan saat data menunjukkan adanya trend. Exponential smoothing dengan adanya trend seperti pemulusan sederhana kecuali bahwa dua komponen harus diperbaharui setiap periode level dan trendnya. Level adalah estimasi yang dimuluskan dari nilai data pada akhir masing-masing periode. Trend adalah estimasi yang dihaluskan dari pertumbuhan rata-rata pada akhir masing-masing periode [9].

Rumus dari double exponential smoothing adalah:

$$
\begin{aligned}
& \mathrm{St}=a * Y t+(1-a) *(S t-1+\mathrm{bt}-1) \\
& b t=\gamma *(\mathrm{St}-\mathrm{St}-1)+(1-\gamma) * b t-1 \\
& \mathrm{Ft}+\mathrm{m}=\mathrm{St}+\mathrm{bt} \mathrm{m} \\
& \mathrm{St}= \\
& \mathrm{Yt}+(1-a)=\text { Neramalan untuk periode } \mathrm{t} . \\
& \mathrm{bt}=\text { trend pada periode ke }-\mathrm{t}
\end{aligned}
$$

I Nyoman Sumerta Yasa : Peramalan Kurs Rupiah ... $a=$ parameter pertama perataan antara 0 dan 1

1 = untuk pemulusan nilai observasi

$\gamma=$ parameter kedua, untuk pemulusan trend

$\mathrm{Ft}+\mathrm{m}=$ hasil peramalan $\mathrm{ke}-\mathrm{m}$

$\mathrm{m}=$ jumlah periode ke muka yang akan diramalkan

\section{Metode Hibrid}

Dalam dunia nyata, data time series jarang murni linear atau non linear. Mereka sering mengandung kedua pola linear dan non linear. Hibridisasi beberapa model mungkin menghasilkan metode yang kuat dan hasil peramalan yang lebih memuaskan [10].

Beberapa hasil perkiraan dimasukkan ke dalam modul perkiraan hibrida dan menghasilkan sinergis hasil perkiraan sebagai output akhir. Dalam proses hibridisasi, strategi hibridisasi yang digunakan yaitu,

$$
\hat{y}_{t}^{\text {Hybrid }}=\alpha \hat{y}_{t}^{R B F}+\beta \hat{y}_{t}^{A R I M A}+\gamma \hat{y}_{t}^{D . E x p}
$$

Dalam persamaan (10), masalah yang timbul adalah bagaimana menentukan parameter $\alpha, \beta$ dan $\gamma$. Umumnya, nilai $\alpha, \beta$ dan $\gamma$, dapat diperkirakan dengan melakukan proses trial and error dimana :

$$
\alpha+\beta+\gamma=1
$$

Dapat juga dicari dengan metode Ordinary Least Square (OLS) yaitu,

$$
\operatorname{Min} Q=\sum_{t=1}^{n}\left(y_{t}-\hat{y}_{t}^{\text {Hybrid }}\right)^{2}
$$

\section{E. Alat Ukur Kesalahan Prediksi}

Menghitung kesalahan dari suatu peramalan sering pula disebut dengan menghitung ketepatan pengukuran (accuracy measures). Dalam praktek ada beberapa alat ukur yang sering digunakan untuk menghitung kesalahan prediksi, salah satunya adalah Mean Absolute Percentage Error.

- MAPE (Mean Absolute Percentage Error)

$$
M A P E=\frac{100}{n} \sum_{t=1}^{n}\left|\frac{A_{t}-F_{t}}{A_{t}}\right|
$$

Dimana :

$$
\begin{aligned}
& \mathrm{A}_{\mathrm{t}}=\text { Data aktual pada waktu } \mathrm{t} \\
& \mathrm{F}_{\mathrm{t}}=\text { Data peramalan pada waktu } \mathrm{t} \\
& \mathrm{N}=\text { Jumlah data }
\end{aligned}
$$

Rumusan di atas melakukan perhitungan perbedaan antara data aktual dan data hasil ramalan. Beda dari hasil perhitungan tersebut diabsolutkan, lalu dihitung ke dalam bentuk persentase terhadap data asli. Hasil dari persentase tersebut kemudian didapatkan nilai rata-rata kesalahannya. Suatu model mempunyai kinerja sangat bagus jika nilai MAPE berada di bawah $10 \%$, dan mempunyai kinerja bagus jika nilai MAPE berada di antara 10\% dan 20\% [11].

p-ISSN:1693 - 2951; e-ISSN: 2503-2372 


\section{METODE PENELITIAN}

\section{A. Rancangan Penelitian}

Pada rancangan penelitian akan dijabarkan gambaran umum sistem yang akan dibuat dan diilustrasikan pada gambar dibawah ini :

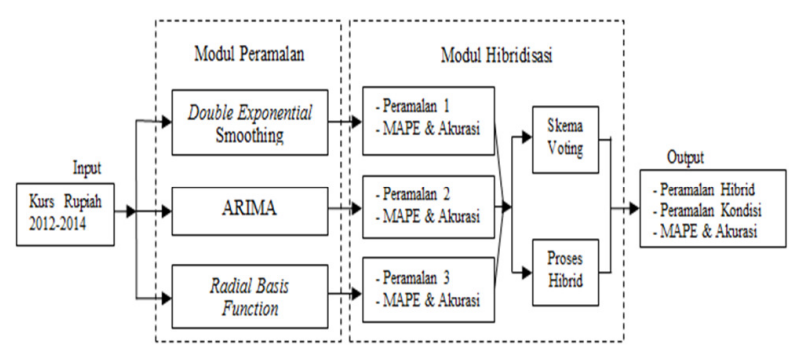

Gambar 2. Gambaran Umum Penelitian

Pada penelitian menggunakan input data perbedaan nilai kurs rupiah terhadap US Dollar. Nilai kurs diramalkan dengan metode Double Exponential Smoothing, Autoregressive Integrated Moving Average (ARIMA), dan jaringan syaraf tiruan Radial Basis Function (RBF). Untuk proses pemilihan hasil peramalan digunakan skema voting dan menggabungkan metode tersebut untuk mendapatkan nilai akhir peramalan.

\section{B. Variabel dan Data Penelitian}

Untuk menunjang proses analisis yang dilakukan oleh pengguna, maka data yang digunakan dalam penelitian ini adalah sebanyak 552 data yang merupakan kurs jual harian Rupiah terhadap US Dollar yang dimulai dari bulan Januari 2012 sampai dengan Maret 2014. Data kurs ini diambil dari website resmi Bank Indonesia di www.bi.go.id. Untuk dapat lebih mudah melihat fluktuasi data maka data diubah dalam bentuk grafik linear.

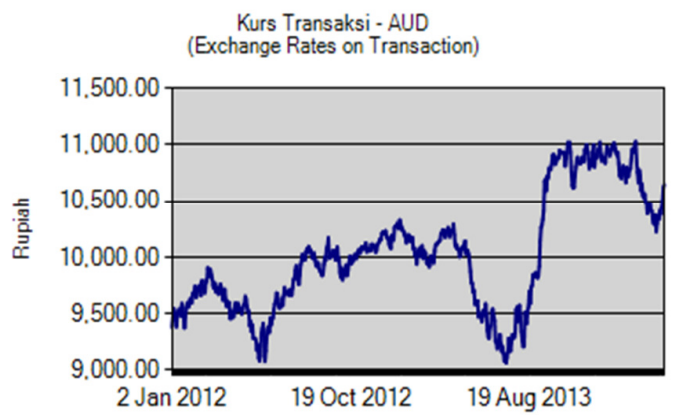

Gambar 3. Grafik Fluktuasi Harian Rupiah Terhadap US Dollar Periode Januari 2012 - Maret 2014

Data dibagi menjadi data pelatihan dan pengujian. Data pelatihan adalah data yang digunakan untuk menentukan data ramalan. Sebagai data pelatihan dipergunakan data kurs jual harian per 1 Januari 2012 sampai dengan kurs harian per 31 Desember 2013. Sedangkan untuk data uji adalah data yang dipergunakan sebagai data pembanding dengan data hasil

I Nyoman Sumerta Yasa : Peramalan Kurs Rupiah ... ramalan. Data uji yang digunakan adalah data kurs harian per 1 Januari 2014 sampai dengan 31 Maret 2014.

\section{Implementasi Peramalan Kurs}

Implementasi peramalan kurs dibangun berbasis GUI menggunakan MATLAB versi 8.1.0.604. Tools editor yang digunakan untuk perancangan GUI di dalam MATLAB adalah GUIDE. Untuk metode Radial Basis Function (RBF) dan ARIMA diaplikasikan menggunakan toolbox yang tersedia pada Matlab, yaitu Neural Network Toolbox dan Econometrics Toolbox.

\section{HASIL PENELITIAN DAN PEMBAHASAN}

\section{A. Metode $R B F$}

Secara umum program peramalan kurs terdapat dua konsep yaitu program training dan prediksi. Pada tahapan training pada peramalan dengan metode $\mathrm{RBF}$, program akan melakukan iterasi sampai dengan jumlah iterasi atau nilai error yang dimasukkan terpenuhi. Pada Matlab membentuk jaringan syaraf tiruan dengan fungsi [12] :

Keterangan :

$$
\text { net }=\text { newrb }(P, T, \text { goal, spread })
$$

$$
\begin{aligned}
& \mathrm{P}=\text { matriks input berukuran RxQ yang berisi } \mathrm{Q} \text { vektor } \\
& \mathrm{T}=\text { matrik kelas target berukuran } \mathrm{SxQ} \text { yang berisi } \mathrm{Q} \\
& \text { vektor target } \\
& \text { Goal }=\text { Mean Squrared Error (default }: 0,0)
\end{aligned}
$$

Spread = lebar fungsi basis radial (default $: 1)$

Nilai goal dalam penelitian hanya menguji nilai goal yang berbeda antara 0,0 sampai dengan 0,1 dengan proses trial and error. Dari jumlah data uji sebanyak 60 data, diperoleh MAPE terbaik yaitu $0,66 \%$ didapat dengan merubah nilai goal menjadi 0,02 .

$$
\begin{aligned}
\text { MAPE }= & \frac{1}{n} \sum_{t=1}^{n} \frac{|Y t-\hat{Y} t|}{Y t} \\
M A P E= & \frac{1}{60}\left(\frac{|10983-10933|}{10983}\right)+\cdots \\
& +\left(\frac{|10650-10497|}{10650}\right) \\
\text { MAPE }= & \frac{39,54}{60} \times 100 \%=0,66 \%
\end{aligned}
$$

Dari hasil peramalan diperoleh data yang benar sebanyak 31 data, sehingga untuk akurasi kondisi menguat dan melemahnya kurs rupiah terhadap US Dollar diperoleh :

$$
\begin{aligned}
\text { Akurasi } & =\frac{\text { Jumlah data Benar }}{\text { Jumlah Data Penguji }} \times 100 \% \\
\text { Akurasi } & =\frac{31}{59} \times 100 \%=52,54 \%
\end{aligned}
$$

p-ISSN:1693 - 2951; e-ISSN: 2503-2372

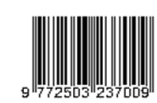




\section{B. Metode ARIMA}

Model dari metode ARIMA dapat diimplementasikan dengan menggunakan fungsi ARIMA dalam Econometrics Toolbox pada Matlab. Berikut adalah fungsi program Matlab untuk peramalan menggunakan metode ARIMA :

$$
\mathrm{Mdl}=\operatorname{arima}(\mathrm{p}, \mathrm{D}, \mathrm{q})
$$

Nilai $p$ dan $q$ dalam penelitian hanya menguji nilai $p$ dan $q$ yaitu 1 sampai dengan 5 yang berbeda dengan proses trial and error. Dari jumlah data uji sebanyak 60 data, diperoleh MAPE terbaik yaitu 3,33\% didapat dengan merubah nilai $p$ dan $q$ menjadi 3.

$$
\begin{aligned}
M A P E= & \frac{1}{60}\left(\frac{|10983-10935|}{10983}\right)+\cdots \\
& +\left(\frac{|10650-11078|}{10650}\right) \\
M A P E= & \frac{199,48}{60} \times 100 \%=3,32 \%
\end{aligned}
$$

Dari hasil peramalan diperoleh data yang benar sebanyak 27 data, sehingga untuk akurasi kondisi menguat dan melemahnya kurs rupiah terhadap US Dollar diperoleh :

$$
\text { Akurasi }=\frac{27}{59} \times 100 \%=45,76 \%
$$

\section{Metode Double Exponential Smoothing}

Pada peramalan dengan metode ini, dipergunakan model Holt's Winters yaitu menggunakan koefisien pemulusan kedua, $\beta$ (beta) yang sama seperti $\alpha$ (alpha), juga bernilai antara nol dan satu, untuk secara berbeda memuluskan trendnya. Beta digunakan untuk merata-ratakan trend yang ada dipersamaan. Hal ini menghilangkan beberapa kesalahan acak yang dapat terjadi pada trend yang tidak dimuluskan.

Untuk mendapatkan nilai terbaik pada peramalan dengan metode ini, maka nilai alpha dan beta dicari dengan menggunakan metode trial and error. Nilai dari alpha dan beta yang akan diuji antara 0,1 sampai dengan 0,9 . Hasil percobaan dengan nilai $\alpha$ dan $\beta$ yang berbeda menimbulkan fluktuasi nilai MAPE. Nilai alpha dan beta dalam penelitian hanya menguji 81 nilai yang berbeda. Nilai MAPE terbaik yaitu $0,94 \%$ didapat dengan merubah nilai $\alpha=0,6$ dan $\beta=0,6$.

$$
\begin{aligned}
M A P E= & \frac{1}{60}\left(\frac{|10983-10918|}{10983}\right)+\cdots \\
& +\left(\frac{|10650-10334|}{10650}\right) \\
M A P E & =\frac{56,48}{60} \times 100 \%=0,94 \%
\end{aligned}
$$

I Nyoman Sumerta Yasa : Peramalan Kurs Rupiah ...
Dari hasil peramalan diperoleh data yang benar sebanyak 31 data, sehingga untuk akurasi kondisi diperoleh :

$$
\text { Akurasi }=\frac{31}{59} \times 100 \%=52,54 \%
$$

\section{Metode Voting}

Untuk menentukan nilai peramalan akhir, digunakan penggabungan hasil ketiga metode dengan teknik skema voting yaitu memilih kondisi dimana di antara ketiga hasil yang memiliki kondisi menguat atau melemah terbanyak. Dari hasil peramalan dengan menggunakan ketiga metode dengan hasil akurasi terbaik, yaitu RBF ( Goal $=0,02)$, ARIMA ( $p=3$ dan $q=3)$ dan Double Exponential Smoothing $(0,6$ dan $\beta=$ $0,6)$ digunakan sebagai acuan untuk pengambilan keputusan dalam meramalkan apakah kurs dalam posisi menguat ataupun melemah.

Jumlah data benar pada proses voting adalah 32 data. Sehingga dapat diperoleh hasil nilai akurasi sebesar :

$$
\text { Akurasi }=\frac{32}{59} \times 100 \%=54,24 \%
$$

\section{E. Metode Hibrid}

Metode hibridisasi adalah proses pengambilan keputusan dengan menggabungkan hasil ramalan dengan kombinasi tiga variabel (antara RBF, ARIMA dan Double Exponential Smoothing) dengan nilai $\alpha, \beta$ dan $\gamma$ sebesar 0,1 - 0,9 dimana nilai kombinasi antar tiga variabel tersebut adalah satu.

Keputusan diambil sesuai dengan hasil ramalan yang yang memiliki kombinasi $\alpha, \beta$ dan $\gamma$ terbaik. Hasil penelitian mendapatkan nilai akurasi MAPE adalah sebesar 0,64\% dengan kombinasi $\alpha=0,8, \beta=0,01$ dan $\gamma=0,19$.

$$
\begin{aligned}
\text { MAPE }= & \frac{1}{60}\left(\frac{|10983-10930|}{10983}\right)+\cdots \\
& +\left(\frac{|10650-10472|}{10650}\right) \\
\text { MAPE }= & \frac{38,45}{60} \times 100 \%=0,64 \%
\end{aligned}
$$

Dari hasil peramalan diperoleh data yang benar sebanyak 30 data, sehingga untuk akurasi kondisi diperoleh :

$$
\text { Akurasi }=\frac{30}{59} \times 100 \%=50,85 \%
$$

Dari hasil peramalan metode-metode diatas, maka perbandingan MAPE dari hasil peramalan dapat dilihat pada tabel berikut : 
TABEL I

PERBANDINGAN NILAI MAPE PERAMALAN

\begin{tabular}{|c|l|c|}
\hline No. & \multicolumn{1}{|c|}{ Metode Peramalan } & MAPE \\
\hline & & \\
1 & RBF & $0,66 \%$ \\
2 & ARIMA & $3,32 \%$ \\
3 & Double Exponential Smoothing & $0,94 \%$ \\
4 & Hibrid & $0,64 \%$ \\
\hline
\end{tabular}

Sedangkan untuk perbandingan dari akurasi kondisi menguat dan melemahnya kurs Rupiah terhadap US Dollar dapat dilihat pada tabel berikut :

TABEL II

PERBANDINGAN AKURASI PERAMALAN

\begin{tabular}{|c|l|c|}
\hline No. & Metode Peramalan & $\begin{array}{c}\text { Akurasi } \\
\text { (Menguat/Melemah) }\end{array}$ \\
\hline \multirow{2}{*}{1} & RBF & $52,54 \%$ \\
2 & ARIMA & $45,76 \%$ \\
3 & Double Exponential & $52,54 \%$ \\
& Smoothing & $54,24 \%$ \\
5 & Voting & $50,85 \%$ \\
\hline
\end{tabular}

Sedangkan perbandingan dari grafik hasil peramalan adalah sebagai berikut :

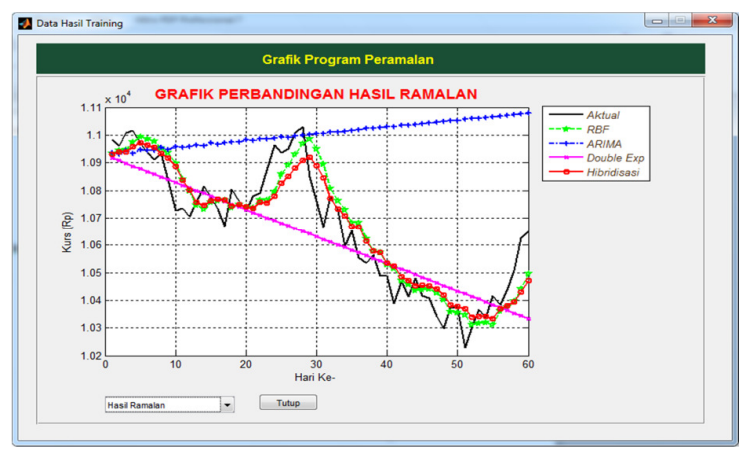

Gambar 4. Grafik Perbandingan Hasil Ramalan

\section{KESIMPULAN}

Peramalan dengan metode RBF, ARIMA, Double Exponential Smoothing diperoleh hasil MAPE berturut turut yaitu $0,66 \%, 3,32 \%, 0,94 \%$. Sedangkan untuk akurasi kondisi menguat atau melemah dari peramalan ketiga metode tersebut adalah 52,54\%, 45,76\% dan 52,54\%. Dari ketiga metode di atas, untuk peramalan kurs yang mempunyai nilai MAPE peramalan terbaik adalah metode RBF.

I Nyoman Sumerta Yasa : Peramalan Kurs Rupiah ...
Dari ketiga metode peramalan, dilakukan peramalan dengan skema voting sehingga diperoleh nilai akurasi kondisi menguat atau melemah sebesar 54,24\%. Sedangkan untuk hasil peramalan dengan metode hibrid diperoleh nilai MAPE peramalan sebesar $0,64 \%$ dan akurasi kondisi menguat atau melemah sebesar 50,85\%. Dari hasil hibridisasi ketiga metode peramalan yaitu RBF, ARIMA dan Double Exponential Smoothing mempunyai nilai MAPE terbaik sebesar $0,64 \%$ dan ini berarti metode hibrid adalah metode yang lebih baik untuk peramalan kurs mata uang.

\section{REFERENSI}

[1] Robinson Sitepu. 2008. Pemodelan Dan Peramalan Deret Waktu Musiman Dengan Pendekatan Filter Bank. Pascasarjana Universitas Sumatera Utara. Medan.

[2] Makridakis, S., Wheelwright, S.C., McGee, Victor E. (1999). Metode dan Aplikasi Peramalan. Jilid Satu.(Edisi 2) diterjemahan oleh Andriyanto, U.S., Abdul, A. Jakarta.

[3] Budi Santosa. 2009 Penerapan Metode Optimasi Exponential Smoothing Untuk Peramalan Debit. Pascasarjana Universitas Diponegoro. Semarang.

[4] Brodjol Sutijo dkk. 2006, "Pemilihan Hubungan Input-Node". Berkala MIPA, 16(1).

[5] Poggio, T., \& Girosi, F. (1990a). Networks for approximation and learning. Proceedings of the IEEE, 78(10), 1481-1497.

[6] Wei,W. W. S. (1994). Time series Analysis, Univariate and Multivariate Methods. Addison-Wesley Publishing Co. Inc.

[7] Hendranata, Anton. 2003. ARIMA (Autoregressive Moving Average), Manajemen Keuangan Sektor Publik FEUI.

[8] Hanke, J.E., Reitsch, A.G. dan Wichern, D.W. 2003.Peramalan Bisnis. Edisi Ketujuh. Alih Bahasa: Devy Anantanur. PT. Prenhallindo. Jakarta.

[9] Alda Raharja. 2010. Penerapan Metode Exponential Smoothing Untuk Peramalan Penggunaan Waktu Telepon Di PT. Telkomsel DIVRE3 Surabaya. Jurnal Sistem Informasi. Institut Teknologi Sepuluh November. Surabaya.

[10] Kin Keung Lai, Lean Yu, Shouyang Wang, and Wei Huang. 2006. Hybridizing Exponential Smoothing and Neural Network for Financial Time Series Predication. ICCS 2006, Part IV, LNCS 3994, pp. 493 500 .

[11] Zainun, N. Y., dan Majid, M. Z. A.,2003. Low Cost House Demand Predictor. Universitas Teknologi Malaysia.

[12] Hongfa Wang, Xinai Xu. 2013. Determination of Spread Constant in RBF Neural Network by Genetic Algorithm. International Journal of Advancements in Computing Technology (IJACT) Vol. 5, No 9 . 